\title{
Psychiatrists should tread cautiously in firearms risk assessment
}

\author{
Robin Bryant (1)
}

COMMENTARY ... GUNS AND PSYCHIATRY ${ }^{\dagger}$

\begin{abstract}
Robin Bryant, PhD, BSc(Hons),
CertEd, is Professor of Criminal

Justice and Policing in the School of

Law, Criminal Justice and Policing at Canterbury Christ Church University,

UK. He has researched and published widely in the field of criminal justice and policing, including analysing the decision-making processes used by police forces to assess the suitability of a person to own a firearm. He is also the co-editor of Blackstone's

Handbook for Policing Students, now in its 14th edition.

Correspondence Professor Robin Bryant, School of Law, Criminal Justice and Policing, Canterbury Christ Church University, North Holmes Road, Canterbury CT1 10U, UK.

Email: robin.bryant@canterbury.ac.uk
\end{abstract}

First received 2 Aug 2019

Accepted 5 Sep 2019

Copyright and usage

(C) The Author 2019

${ }^{\dagger}$ See this issue.

\begin{abstract}
SUMMARY
Ann Mortimer's article on gun control and licensing in the UK makes some important points concerning the role of the psychiatrist during the licensing process and the complexities surrounding this. However, the risk-assessment framework (describing low, medium and high risk) that she proposes is problematic.
\end{abstract}

\section{DECLARATION OF INTEREST}

None.

\section{KEYWORDS}

Firearms licensing; risk assessment; guns.

In this issue, Ann Mortimer (2019) examines 'guns and psychiatry' and focuses on what psychiatrists need to know. The article provides a clear exposition of the background to gun control in the UK and the processes employed by police forces when granting a certificate to legally possess a shotgun or firearm. Mortimer makes some important points concerning the complexities surrounding firearms licensing, for example in terms of the omission of certain cognitive disorders from the Home Office list of medical conditions that licence applicants must declare.

\section{A 'wicked problem'}

To grant or deny a member of the public the right to own and use a firearm is one of the most onerous decisions that the police are required to make: it falls squarely within the realm of a 'wicked problem'. The Home Office provides guidance to police forces on how to implement statute and the College of Policing also advises on the risk factors to be considered: these include the medical and mental health of the applicant (College of Policing 2016). Although the police carry out their licensing duties effectively, mistakes can and do happen, as illustrated at the inquest into the deaths of Christine and Lucy Lee in 2014 (killed by an individual using legally held shotguns returned to him by local police) (BBC News 2019). There have also been highly critical national reports on firearms licensing, with Her Majesty's Inspectorate of Constabulary concluding in 2015 that the way that police forces managed firearms licensing risk was 'unsatisfactory' (HMIC 2015). Improvements have been made since 2015, but problems remain. For example, it is unfortunately not the case that a home visit is always undertaken for renewals (as stated in Mortimer's article), as many police forces have now adopted renewal interviews by telephone.

\section{What we know (and don't know) about the topic}

It is probably true that firearms certificate holders are, as Mortimer claims, 'one of the most lawabiding sections of society', but there is little research to corroborate this. Mortimer's personal reflection that she finds that 'most certificate holders are extremely reluctant to disclose low mood, or indeed any mental health problem, for fear of confiscation of their firearms and revocation of their certificates' suggests the police are right to remain vigilant about simply assuming the ongoing 'trustworthiness' of certificate holders. Mortimer also points to a $2.5 \%$ refusal rate in 2017-2018 for new applications as a signifier of 'good standing'. However, this conflates the figures for firearms (2.2\%) and shotguns (2.9\%). There are many more shotgun certificates issued than firearm certificates. When the two percentages are combined it means that there were approximately 1000 'unsuitable' people in England and Wales attempting to gain the right to hold a gun licence in 2017-2018 (based on Home Office 2018: Tables 2 and 3).

Although it is correct (as Mortimer claims) that the majority of crimes in which firearms are used involve illegally held handguns, underlying trends are also important. Handguns remained relatively stable as a proportion of such crimes between 2008 and 2018 (at about 43\%), but the proportion of shotguns used increased from 6 to 10\% (Office for National Statistics 2019: Table 2). Furthermore, in terms of illegal firearms discharges during the 2017-2018 reporting period, shotguns actually accounted for a greater proportion than handguns 
(National Ballistics Intelligence Service, personal communication, 2019).

\section{How far should the psychiatrist's role extend in decision-making?}

The medical profession clearly has an important role to play in assisting police decision-making. General practitioners (GPs) and psychiatrists provide police with factual information concerning relevant medical conditions. However, it is for the police to assess any mental health information provided alongside crime, intelligence and other reports available to them (and often them alone). Medical practitioners are not expected to offer advice on the suitability of their patient to own a gun, but to work with police so that the latter are able to make an informed decision. Mortimer makes this point in the 'The GP's role' section, but I felt that some other parts of the article 'muddied the waters'. A fundamental difference between the roles of psychiatrists and police in the licensing process is that the latter will be expected to adopt an 'investigative mindset'. Example 2 in the 'High risk' section of the article illustrates why this is important. The assumption in the example is that the situation is resolved through the cooperation of the patient's brother. However, in cases like this the police will also risk assess non-medically related factors, such as whether there is a spare set of keys to the safe. The patient's psychiatrist should also not, in my view, become involved in giving advice on the storage of a certificate holder's guns (as appears to be the case with the advice offered in the 'Medium risk' section).

\section{Should psychiatrists carry out firearms risk assessments?}

Mortimer argues that '[t]he risks conferred by mental disorder in certificate holders comprise, in summary, security breaches, suicide and homicide'. In terms of homicide, as readers of this journal will appreciate, most people with mental health problems do not act violently, with or without a weapon. The article's emphasis on suicide as a risk is understandable, from a patient-care perspective. However, there are significant dangers to the public from guns being lost, stolen, misused or used to frighten and control others (the simple existence of a weapon in a house may be intimidatory). Mental illness is clearly a risk factor for a number of these dangers. The National Ballistics Intelligence Service (NABIS) reports that, for the 2017-2018 period, 430 firearms were recorded on the NABIS database as having been stolen, 305 of which were shotguns (NABIS, personal communication, 2019). In 2016 the MP Jo Cox was shot using a modified rifle stolen from someone who held it legally.

In general terms, is unclear to me whether the 'low', 'medium' and 'high risk' framework described by Mortimer refers to dangers to the patient (e.g. suicide), to others (e.g. intimidation of a partner of the gun-holder) or to a medical practitioner (the reference to 'significant personal risk'). Indeed, I have misgivings regarding any firearms risk assessment carried out by non-police, and particularly if it leads to actions such as a patient being advised by their psychiatrist to 'cease their access to firearms'. In these litigious times (Birks 2018) even the most well-intentioned medical professional can find their interventions challenged post hoc.

\section{References}

Birks Y, Aspinal F, Bloor K (2018) Understanding the Drivers of Litigation in Health Services. University of York.

College of Policing (2016) Major Investigation and Public Protection: Firearms Licensing. College of Policing (https://www.app.college.police. uk/app-content/major-investigation-and-public-protection/firearmslicensing/). Accessed 17 July 2019

HMIC (2015) Targeting the Risk: An Inspection of the Efficiency and Effectiveness of Firearms Licensing in Police Forces in England and Wales. HMIC (https://www.justiceinspectorates.gov.uk/hmicfrs/wp-content/up loads/firearms-licensing-targeting-the-risk.pdf).

Home Office (2018) Firearm and Shotgun Certificates in England and Wales, Financial Year Ending 31 March 2018: Data Tables. Home Office.

Mortimer AM (2019) Guns and psychiatry: what psychiatrists need to know. BJPsych Advances, this issue.

Office for National Statistics (2019) Offences Involving the Use of Weapons: Data Tables (Year Ending March 2018). ONS.

BBC News (2019) Farnham puppy farm murders: Police failings 'contributed' to killings. BBC, 21 June (https://www.bbc.co.uk/news/uk-englandsurrey-48722616). Accessed 17 July 2019 